\title{
El rol del lenguaje en Humberto Maturana: la importancia de la inclusión en el discurso
}

\author{
Karen Urrejola Corales \\ Pontificia Universidad Católica de Chile, Chile
}

os aportes de Humberto Maturana al mundo de la lingüística permiten reflexionar sobre el rol del lenguaje en la sociedad y sobre cómo se construye el concepto de realidad en esta. La importancia que el autor da al acto mismo de conversar, como la posibilidad de inclusión de distintas cosmovisiones y grupos sociales, ilumina problemáticas actuales sobre el discurso y los diferentes actores que lo conforman. En este breve simposio se hará referencia a algunos de los principales conceptos propuestos por Maturana en el ámbito de la lingüística y su relación con cuestiones sociales - que el mismo autor evidenció en muchos de sus textos- y que aún hoy en día son fuente de discusión en Chile y el mundo.

\section{El concepto de lenguaje en Maturana}

Para Maturana (1995a), el lenguaje es el mecanismo fundamental de interacción social. Así, es la conducta primaria de las personas en las sociedades que ellas conforman: "Nuestra individualidad como seres

Karen URRejola es candidata a Doctora en Lingüística de la Pontificia Universidad Católica de Valparaíso, Chile; Magíster en Lingüística y Licenciada en Letras Hispánicas de la Pontificia Universidad Católica de Chile. Actualmente es académica de la Facultad de Letras, Pontificia Universidad Católica de Chile. Dirección: Vicuña Mackenna 4860, Macul, Santiago, Chile, CP 7820436. Email:kuc@uc.cl. 
humanos es social y al ser humanamente social es lingüísticamente lingüística, es decir, está inmersa en nuestro ser, en el lenguaje" (Maturana 1995a, 78). De este modo, el lenguaje sería este fluir recursivo de coordinaciones conductuales consensuales que se da en sociedad (Maturana 1995a). Así, existimos en un mundo social que es definido a través del lenguaje, pues es en este donde nos realizamos como seres vivos y donde subyace nuestra organización y representación social (Maturana y Varela 1984).

A partir de lo anterior, el autor concluye que el ser humano es el que otorga los significados a las palabras, entendidas como nodos de coordinaciones conductuales consensuales, siempre como observador inmerso en este lenguaje. Dicho de otra manera, asignamos significados a los gestos, conductas o sonidos desde la relación de coordinación conductual consensual donde vemos que estos participan, es decir, desde la interacción misma que los envuelve y que percibimos (Maturana 1995b). De este modo, las palabras tendrían significado en este fluir de coordinaciones dadas por la propia experiencia del observador, a través de su participación en la sociedad.

Desde esta mirada, Maturana (1995b) postula el lenguajear como un neologismo para hacer referencia al acto de estar en el lenguaje mismo, sin referirse específicamente al habla, sino al concepto de estar en este sistema. En otras palabras, se refiere al operar en este lenguaje, pues somos en el lenguaje. A partir de lo anterior, Maturana (1995b, 85) indica:

lo que un observador ve como el contenido de un lenguajear particular, está en el curso que siguen las coordinaciones conductuales consensuales que tal lenguaje involucra, en relación con el momento en la historia de interacciones en que ellas tienen lugar.

Así, el rol del observador es fundamental y, al mismo tiempo, se ve influido por este, ya que el acto mismo de participar en el lenguaje gatiIla cambios estructurales en las dinámicas sociales (en su amplio concepto) del que el observador es parte (Maturana 1995b).

El lenguaje, entonces, configura nuestra realidad: "es dentro del lenguaje mismo que el acto de conocer, en la coordinación conductual que el lenguaje es, trae un mundo a la mano [...] en el devenir del mundo lingüístico que construimos con los otros seres humanos" (Maturana y Varela 1984, 155). Así, Maturana (1995c) postula la existencia de una objetividad sin paréntesis y una objetividad entre paréntesis. La primera da 
cuenta de un universo y realidad independientes de nuestro lenguaje, mientras que la segunda admite varias realidades, y es en este lenguajear y conversar donde se genera esta realidad (Maturana 1995c). Es en esta segunda objetividad donde el acto de conversar y reflexionar se vuelve fundamental, y es a la que adscribe el autor. De esta manera, es la reflexión en torno a nuestro lenguaje lo que nos permite tanto contemplar nuestro mundo e identidad como acceder al mundo e identidad del otro (Maturana 1995a, 1995b).

\section{La invisibilización del 'otro' en el discurso}

Si entendemos, entonces, que el lenguaje se da en este fluir de interacciones recursivas de coordinaciones conductuales consensuales, y que es en este que creamos realidad, en conjunto con otros, la reflexión en torno a aquel es fundamental (Maturana 1995a, 1995b). La contraparte, en cambio, nos llevaría por un camino distinto. El lenguaje, sin la reflexión en torno a este ni en la disposición a conversar con el otro, es lo que también nos puede distanciar y llevar a la exclusión del otro: "Pero el lenguaje es también la caída del ser humano, al permitir las cegueras frente al ser biológico que traen consigo las ideologías [...] nuestras ideologías justificativas nos ciegan frente a nosotros mismos y los demás" (Maturana 1995a, 81). El apego exacerbado a nuestras ideologías nos lleva a negar al otro y nos cerramos al acto de conversar y reflexionar sobre el mundo que compartimos con el resto. En otras palabras, al negar al otro, invisibilizamos otras cosmovisiones y representaciones de la realidad.

Un ejemplo de esta invisibilización se evidencia en el estudio de Ibáñez (2010), a partir de trabajos previos con Maturana, en el que compara los contextos interaccionales de aula entre niños de clase media de Santiago y comunidades mapuche rurales del sur de Chile que asisten a un mismo colegio, desde la relación del desarrollo del lenguaje y la concepción de mundo de los estudiantes. La autora indica que la invisibilización de los significados, expresados en la lengua, que traen los niños de comunidades mapuche, es producto de una cultura discriminadora de las escuelas, desde una visión cerrada del lenguaje, que contempla una sola realidad. De esta manera, expone la necesidad de una mirada que abarque las distintas culturas, expresadas en las inte- 
racciones lingüísticas y conductuales de los niños y las niñas presentes en el aula.

La invisibilización del otro en el discurso no es nueva y se da en diferentes áreas como la escuela, la prensa, las redes sociales, las leyes e incluso la conversación cotidiana. La invisibilización en el discurso social de grupos y de los actos discriminatorios que han sufrido (como es el caso de disidencias sexuales, de las mujeres y su historia, de inmigrantes, indígenas y sectores vulnerables), así como de la manera en que se representan en los discursos, muchas veces desde una mirada negativa, es parte de una violencia estructural (Van Dijk 1997, 2001; Butler 2002; Sorribas y Cabral 2010; Valverde 2013; Cornejo 2017; Varela 2019, entre muchos otros).

Así, el dar nombre a actos de discriminación y violencia de forma específica es visibilizarlos socialmente. Por ejemplo, el hecho de dar un nombre a la agresión psicológica o física en las escuelas como bullying (Olweus 1978), es dar un lugar a estos actos en nuestro discurso, y es lo que incide en que comencemos a conversar del tema. De este modo, conceptos como racismo, machismo, homofobia son palabras que en su uso visibilizan estos actos (y a quienes son víctimas de estos) y abren la oportunidad de conversar/reflexionar en torno a ellas y sus respectivos contenidos.

De este modo, para Maturana (1989) el acto de conversar es fundamental, ya que todo quehacer humano se da en este acto y es en este donde se da la posibilidad de aceptar la realidad del otro. Desde esta mirada, Maturana y Varela $(1984,163)$ indican lo siguiente: "Lo que cabrá, entonces, será la búsqueda de una perspectiva más abarcadora, de un dominio experiencial donde el otro también tenga lugar y en el cual podamos construir un mundo con él". La presencia del otro y su realidad en nuestro discurso, es necesaria para poder convivir en respeto y armonía, sin negarlo y sin negarla frente a ideologías creadas a priori.

Es a partir de lo anterior que se dan los esfuerzos actuales por incluir a todos y todas en nuestro discurso, sin imponer ideologías o 'conceptos' desde una sola mirada. Así, no son menores las discusiones sobre cómo nombrar a personas en situación de discapacidad (García et al. 2013), distintas realidades e identidades sexuales (Ramírez y García 2018), o culturales, en su amplio espectro y diversidad. El 'cómo quiero ser nombrado o nombrada' da cuenta de 'cómo soy parte' de la realidad que integro, 
y cuál es mi identidad en esta. Dar espacio a todos y todas en nuestro discurso es dar espacio a la inclusión social y a las estructuras que nos conforman y conforman nuestra realidad, que es siempre compartida.

Maturana y Varela $(1984,163)$ proponen, así, la necesidad de la reflexión sobre la legítima presencia del otro en nuestros discursos:

Todo acto humano tiene lugar en el lenguaje. Todo acto en el lenguaje trae a la mano el mundo que se crea con otros en el acto de convivencia que da origen a lo humano; por esto todo acto humano tiene sentido ético. Este amarre de lo humano a lo humano es, en último término, el fundamento de toda ética como reflexión sobre la legitimidad de la presencia del otro.

Así, el acto de visibilizar al otro y su historia, en nuestro discurso, es fundamental para hacerlo parte y validar sus vivencias y cosmovisión. Es la manera en que estos autores proponen que se debe hacer uso ético del lenguaje en el cual 'nos movemos'.

Como fue posible apreciar en este breve simposio, los aportes de Maturana a la lingüística se basan en la necesidad de reflexionar, en términos del autor lenguajear y conversar, sobre nuestra realidad, y presentar cómo esta se construye a través de tales actos. Hoy en día aún existe, en el discurso, en sus distintos medios de soporte, la invisibilización, y, por tanto, exclusión y negación de diversos grupos, de sus historias y de las discriminaciones que han vivido, y que persisten. De este modo, si bien el autor, en conjunto con otros y otras escritoras, ha evidenciado esto en sus obras, se trata de una problemática que está lejos de estar cerrada en nuestra sociedad. Por el contrario, propuestas y reflexiones como las de Maturana, al iluminar estos hechos, dan base para seguir abogando por la necesidad de una mirada más abarcadora e inclusiva en nuestros discursos.

\section{Bibliografía}

Butler, J. 2002. Cuerpos que importan. Sobre los límites materiales y discursivos del 'sexo'. Buenos Aires: Paidós.

Cornejo, J. 2017. Disidencias sexuales en el sistema escolar chileno: represión e invisibilización. Educação e Pesquisa 43(3), 879-898.

García, I., Romero, S., Aguilar, C., Lomeli, K. y Rodríguez, D. 2013. Terminología internacional sobre la educación inclusiva. Actualidades Investigativas en Educación 13(1), 182-211. 
Ibáñez, N. 2010. El contexto interaccional y la diversidad en la escuela. Estudios Pedagógicos 36(1), 275-286.

Maturana, H. y Varela, F. 1984. El árbol del conocimiento: las bases biológicas del entendimiento humano. Santiago: Editorial Universitaria.

Maturana, H. 1989. Lenguaje y realidad: El origen de lo humano. Archivos de Biología y Medicina Experimentales 22, 77-81.

Maturana, H. 1995a. 'Biología del fenómeno social' (69-83). En J. Luzoro (comp.), Desde la biología a la psicología. Santiago: Editorial Universitaria.

Maturana, H. 1995b. 'Ontología del conversar' (84-95). En J. Luzoro (comp.), Desde la biología a la psicología. Santiago: Editorial Universitaria.

Maturana, H. 1995c. La realidad ¿objetiva o construida? Fundamentos biológicos de la realidad. Santiago: Anthropos/Iteso/Universidad Iberoamericana.

Olweus, D. 1978. Aggression in the Schools: Bullies and Whipping Boys. Washington DC: Hemisphere.

Ramírez, G. y García, R. 2018. La modificación del cuerpo transgénero: experiencias y reflexiones. Andamios 15(37), 303-324.

Sorribas, P. y Cabral, X. 2010. Acciones colectivas y expropiación de bienes naturales. Tácticas de resistencias a la invisibilización mediática y los reenmarcamientos estatales. Nómadas 33, 147-163.

Valverde, S. 2013. De la invisibilización a la construcción como sujetos sociales: el pueblo indígena mapuche y sus movimientos en Patagonia, Argentina. Anuario Antropológico 38(1), 139-166.

van Dijk, T. 1997. Discurso, cognición y sociedad. Signos. Teoría y Práctica de la Educación 22, 66-74.

van Dijk, T. 2001. Discurso y racismo. Oxford: David Goldberg \& John Solomos.

Varela, I. 2019. Nunca más un México sin nosotras. Feminismo y mujeres afromexicanas. Política y Cultura 51, 105-124. EP 